\title{
Projectile balloting attributable to gun tube curvature
}

\author{
Michael M. Chen* \\ US Army Research Laboratory, AMSRD-ARL-WM-BC, Aberdeen Proving Ground, MD 21005, USA
}

Received 22 January 2008

Revised 6 January 2009

\begin{abstract}
Transverse motion of a projectile during launch is detrimental to firing accuracy, structural integrity, and/or on-board electronics performance of the projectile. One manifest contributing factor to the undesired motion is imperfect bore centerline straightness. This paper starts with the presentation of a deterministic barrel model that possesses both vertical and lateral deviations from centerline in accordance with measurement data, followed by a novel approach to simulating comprehensive barrel centerline variations for the investigation of projectile balloting ${ }^{1}$ motions. A modern projectile was adopted for this study. In-bore projectile responses at various locations of the projectile while traveling through the simulated gun tubes were obtained. The balloting was evaluated in both time and frequency domains. Some statistical quantities and the significance were outlined.
\end{abstract}

Keywords: Projectile balloting, barrel centerline variations, gun tube curvature modeling, design of experiments

\section{Introduction}

Balloting refers to any transverse motion of a projectile traveling in a gun tube. Substantial in-bore balloting could lead to erratic launch conditions that cause premature tumbling and short trajectory, i.e., greatly reduce the firing accuracy. This issue must be addressed for a modern weapon such as mid-range precision guided projectile in which the effectiveness of the ammunition is mainly driven by hitting accuracy and consistency. Generally speaking, the causes of projectile balloting may be attributable to the following factors: asymmetric pressure applied at projectile base, projectile center of gravity (c.g.) and principal axis offset from bore centerline, insufficient stiffness of projectile-gun interface, engraving interaction among projectile components, and imperfect straightness of gun barrel centerline. Several researchers were dedicated to this matter over the past few decades. For instance, Walker [1] developed a mathematical approach to calculating the causes of severe balloting attributable to gun tube damage. Walker's theory was then adopted by Fansler [2], who discussed the possibility for balloting-energy growth. In addition, Plostins et al. [3-5] investigated the effects of sabot bore-rider stiffness on launch dynamics of the XM881 and M900 projectiles recently. Newill et al. [6] evaluated projectile responses at shot exit attributable to certain types of distorted form of an M256 gun tube. The efforts have also been extended to the applications of electro-magnetic launchers by Chu and Lodge [7,8]. This paper focused on creating a complete profile of gun barrel centerline variations. The attempt was to gain a better understanding of the balloting motion of a projectile under the influence of the variation profile.

It has been known that the barrel centerline variations may have a significant impact on launch dynamics [9-11]. In general, the variations may be attributed to a variety of factors, such as manufacturing tolerance/error, uneven cooling, non-uniform wall thickness, erosion, and vibrations. Because of additional uncontrollable factors, the gun

\footnotetext{
*Corresponding author. Tel.: +1 410306 0795; E-mail: michael.m.chen@ arl.army.mil.

${ }^{1}$ Balloting consists of two types of motion: a translation of the center of gravity (c.g.) perpendicular to the line of fire, and an angular rate about the c.g.
} 
Table 1

Physical and mechanical properties of a hit-to-kill projectile system

\begin{tabular}{cllcccc}
\hline Part No. & Part name & Material & Density $\left(\mathrm{kg} / \mathrm{mm}^{3}\right)$ & Elastic modulus $(\mathrm{MPa})$ & Poisson's ratio & Weight $(\mathrm{kg})$ \\
\hline 1 & Bore & Steel & $7.75 \mathrm{E}-06$ & $1.96 \mathrm{E} 05$ & 0.28 & - \\
2 & Body \& Fin & Steel & $7.75 \mathrm{E}-06$ & $1.96 \mathrm{E} 05$ & 0.28 & $5.03 \mathrm{E}-01$ \\
3 & Penetrator & Tungsten & $1.80 \mathrm{E}-05$ & $3.65 \mathrm{E} 05$ & 0.28 & $2.71 \mathrm{E}-01$ \\
4 & Windscreen & Aluminum & $3.60 \mathrm{E}-06$ & $6.90 \mathrm{E} 04$ & 0.33 & $9.51 \mathrm{E}-03$ \\
5 & Sabot & Aluminum & $3.60 \mathrm{E}-06$ & $6.90 \mathrm{E} 04$ & 0.33 & $4.07 \mathrm{E}-01$ \\
6 & Cavity & Electronics & $7.10 \mathrm{E}-07$ & $1.00 \mathrm{E} 04$ & 0.35 & $4.85 \mathrm{E}-02$ \\
\hline
\end{tabular}

(a)

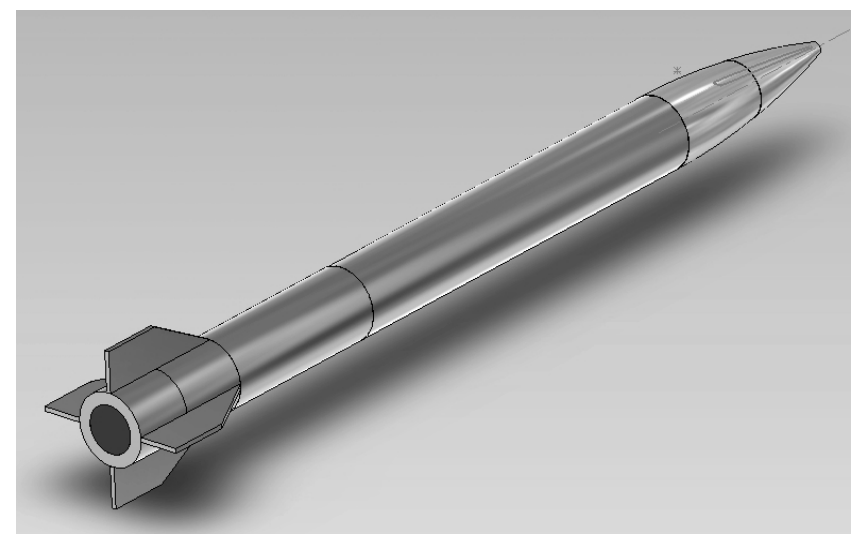

(b)

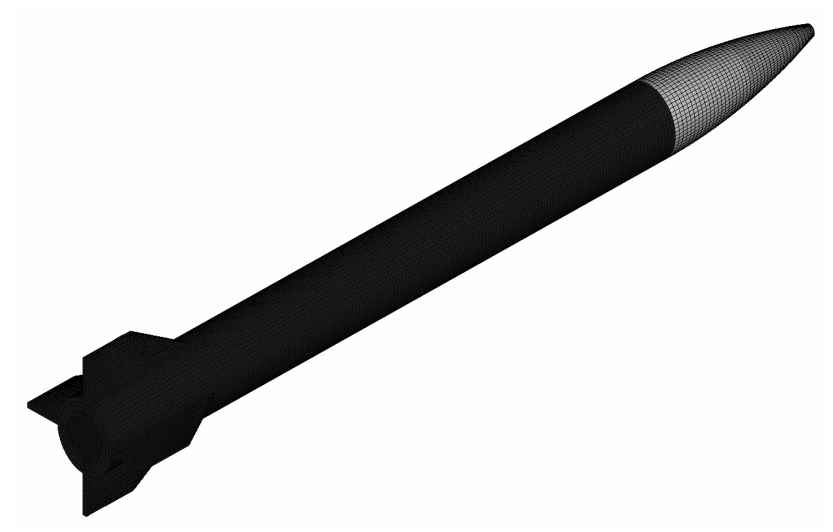

Fig. 1. Display of a (a) fin-stabilized projectile model and (b) finite element representation.

tubes that are used on the battlefield exhibit a higher degree of centerline variations. Thus, a thorough study in understanding projectile balloting subject to various gun tube curvatures is needed. This paper employed a parametric model that can be used to define a wide range of deviations for the bore center straightness of gun barrels. With the model, an array of gun barrels was generated through computer simulations, which constituted a good representation of regular barrel centerline variations profile. Subsequently, the oscillations of a projectile, while traveling through the simulated gun barrels, were investigated in both time and frequency domains.

This paper adopted a fin-stabilized projectile system for the study of balloting behavior. A finite element representation of the projectile based on a three-dimensional (3-D) solid model was created and is shown in Fig. 1. The projectile system consisted of windscreen, penetrator, body, fin, sabot, electronics and obturator. The body and the fin were made of steel, the sabot of aluminum, the obtuator of nylon, and the penetrator of tungsten. Detailed physical and material properties of the projectile are provided in Table 1. 
(a)

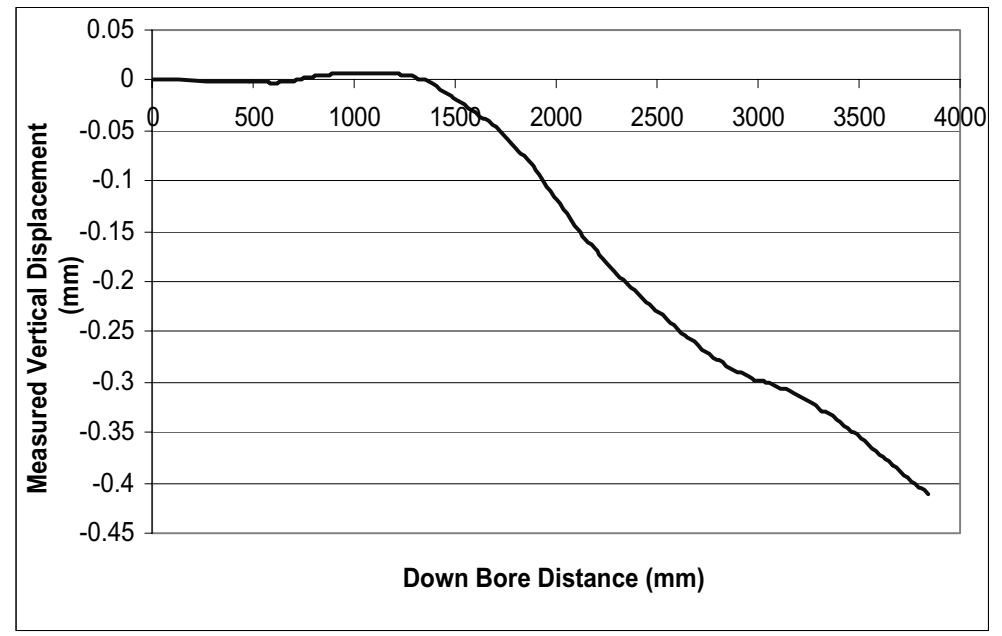

(b)

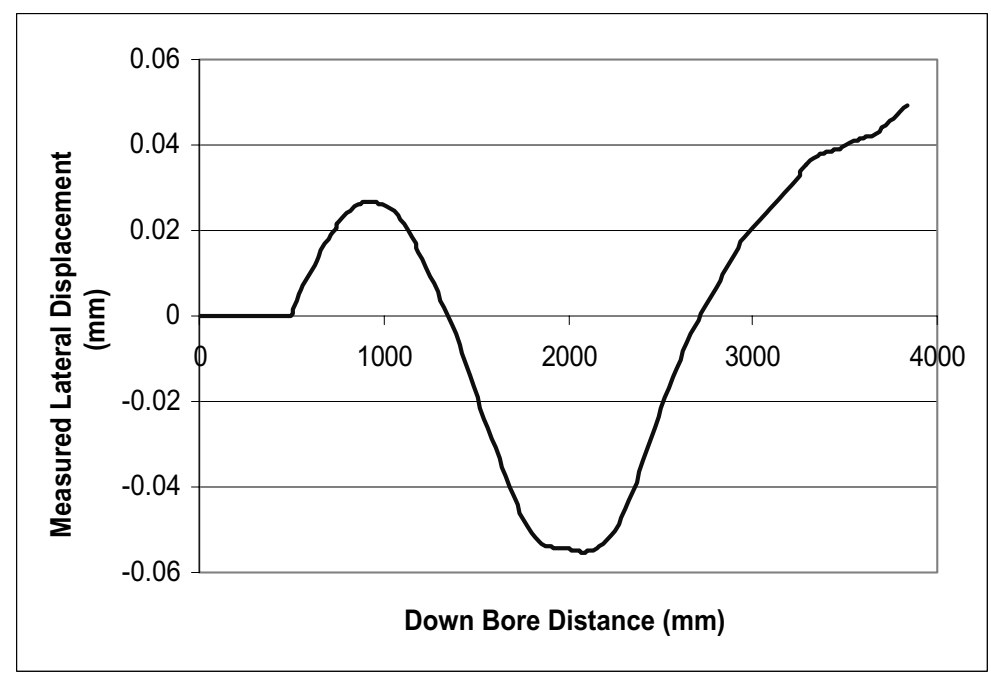

Fig. 2. Measured barrel centerline variations in (a) vertical and (b) lateral directions.

\section{Gun tube curvature modeling}

\subsection{Deterministic modeling and analysis}

A smooth gun barrel that has a total length of $3840 \mathrm{~mm}$ was adopted and modeled. The measured vertical and lateral centerline variations along the down-bore distance from the rear face of the tube are shown in Fig. 2(a) and (b), respectively. It appears that the barrel had a slightly upward displacement between the $700 \mathrm{~mm}$ and $1300 \mathrm{~mm}$ locations and then went downward all the way until the muzzle, where a maximum displacement of $0.41 \mathrm{~mm}$ existed. No lateral deviation from the centerline exhibited before $500 \mathrm{~mm}$ place. A sinuous wave type of lateral displacement was recorded. To be able to model the gun barrel in accordance with the measured centerline variations, a computer program called BoreMorpher was developed. BoreMorpher adopted a third order polynomial to fit the data of a selected segment. The number of segments was determined on the basis of the changes of the curvature and the number of measurement points along the gun barrel. In other words, the more complex the barrel centerline variations are, the more segments, i.e., the more polynomials, will be needed. The bore displacement value and the 
(a)

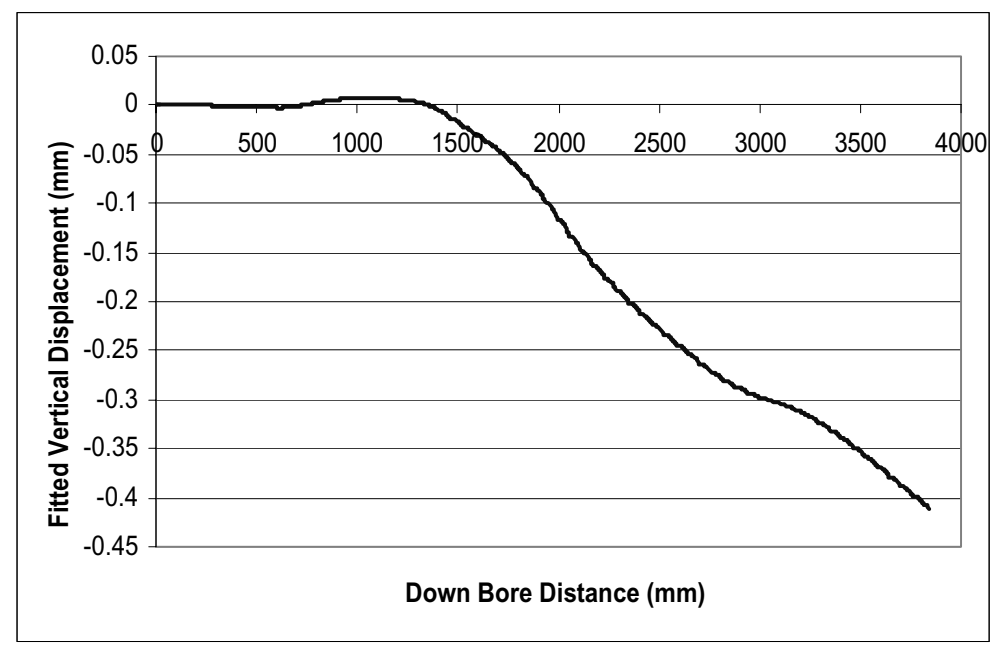

(b)

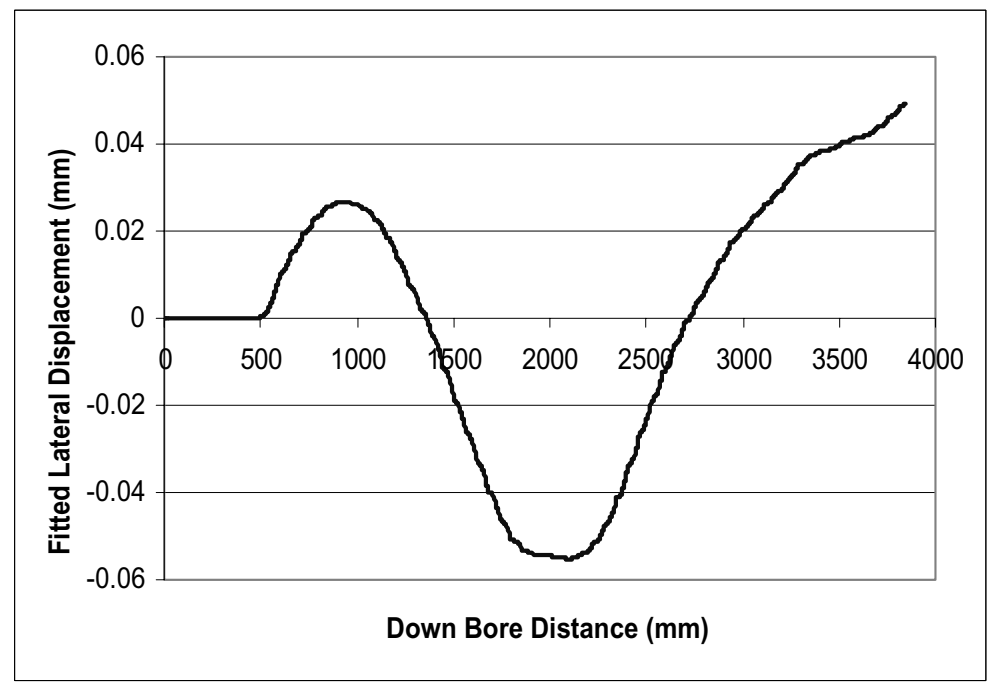

Fig. 3. Fitted barrel centerline variations in (a) vertical and (b) lateral directions.

slope are ensured to be continuous among segments along the gun tube. A third order polynomial can be expressed as

$$
Y=a_{0}+a_{1} X+a_{2} X^{2}+a_{3} X^{3}
$$

with the boundary conditions

$$
Y=Y_{0}, Y_{0}^{\prime}=0 \text { as } X=X_{0} \text { and } Y=Y_{1}, Y_{1}^{\prime}=0 \text { as } X=X_{1}
$$

the coefficients $a_{0}, a_{1}, a_{2}$, and $a_{3}$ can then be solved.

Based on the fitted polynomials, the deviated displacement at an axial nodal location can be computed. Subsequently, all the nodes in the cross section of the axial location were displaced with the computed amount. The "morphing" was performed throughout the finite element model of the gun tube. Figure 3(a) and (b) demonstrate the fitted curves for the vertical and lateral centerline variations, respectively. It can be seen that an excellent agreement with the measured data was achieved. 
(a)

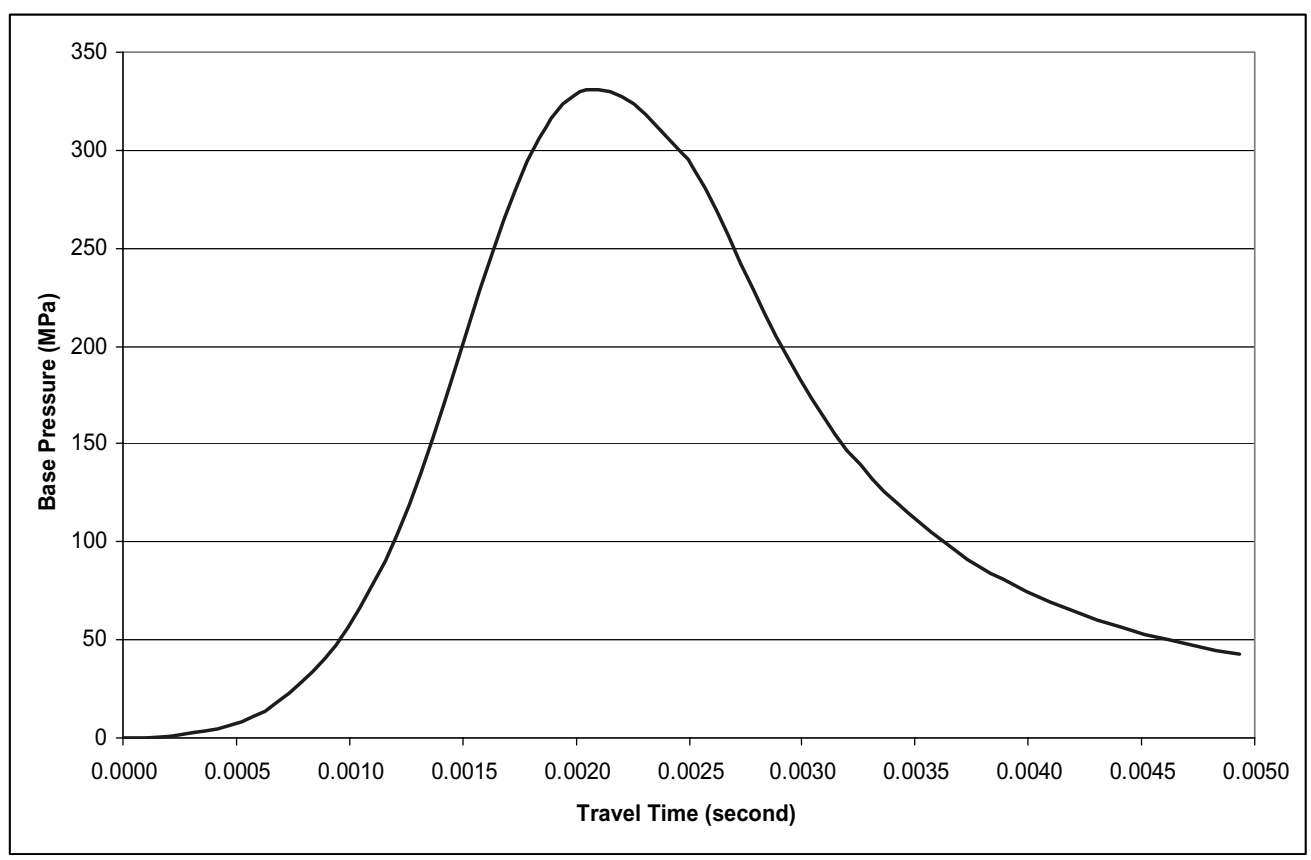

(b)

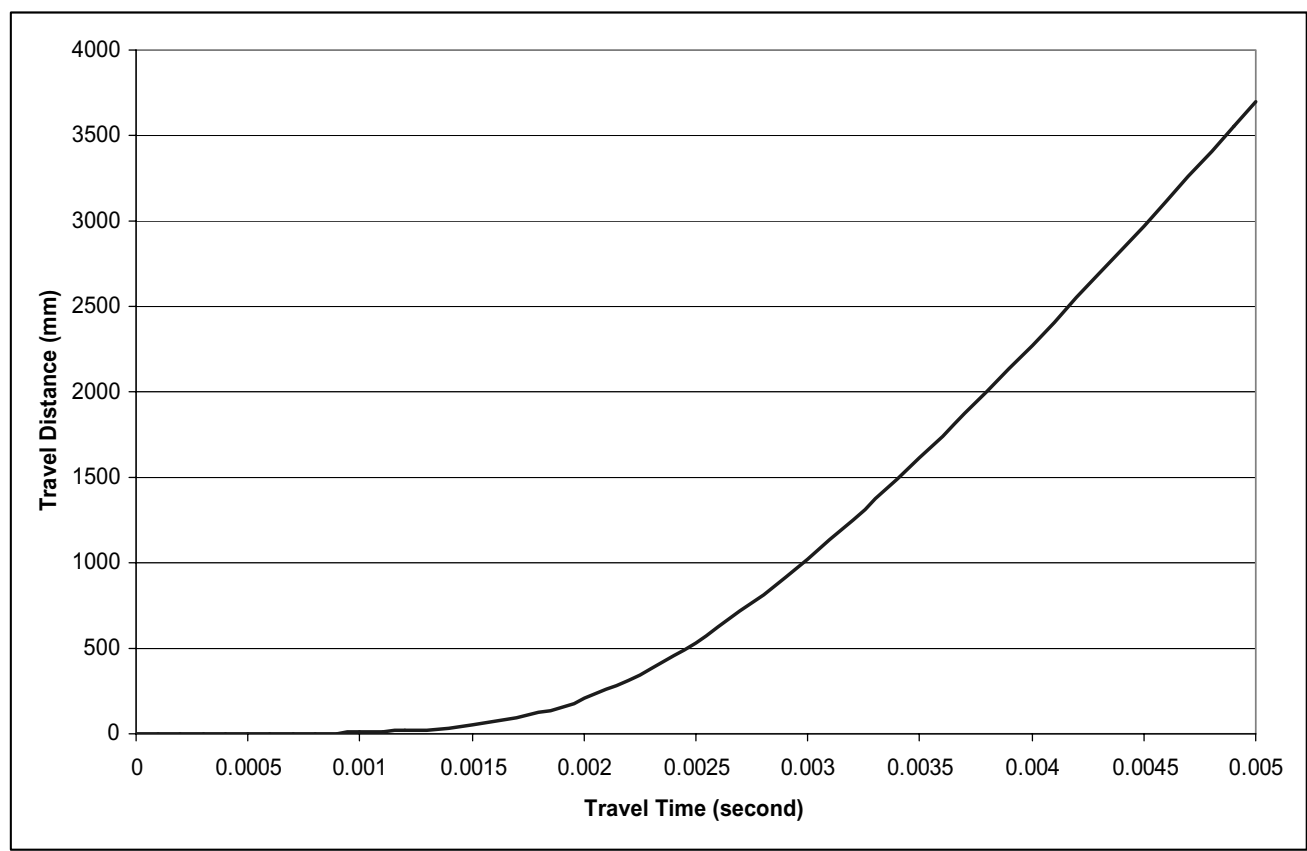

Fig. 4. Display of (a) base pressure-time curve and (b) projectile travel distance-time curve.

An in-bore dynamic analysis was then performed with the morphed gun barrel. A pressure-time curve given in Fig. 4(a) was applied at the projectile in the chamber area. The pressure curve had a total duration of $5 \mathrm{~ms}$ with a peak value of $330 \mathrm{MPa}$ that occurred $2 \mathrm{~ms}$ from ignition. Figure 4(b) describes the in-bore travel distance of the 


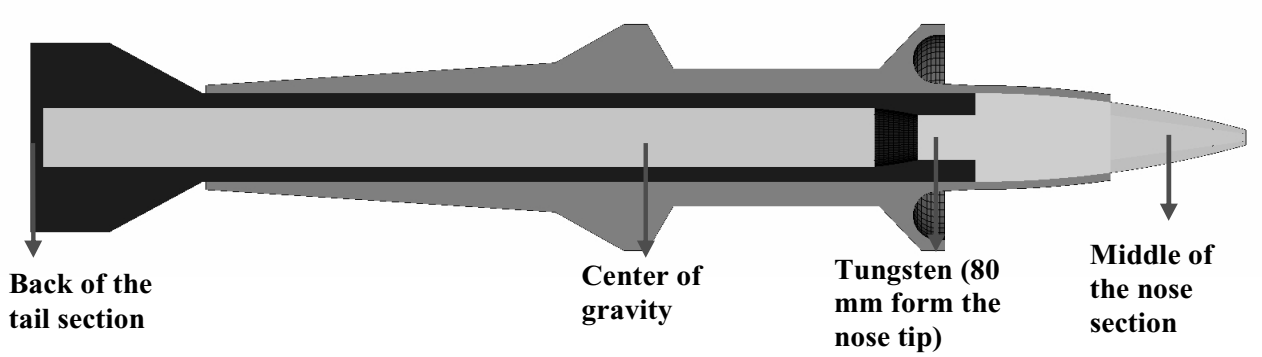

Fig. 5. Illustration of four evaluation points for transverse responses, i.e. middle of the nose section, tungsten penetrator $(80 \mathrm{~mm}$ from the nose tip), center of gravity, and back of the tail section.

projectile against time. A few points of the projectile were selected to obtain the transverse responses attributable to the flexibility of the projectile body. Because electronic devices, such as seeker, were installed inside the windscreen, a point on the middle of the nose section as illustrated in Fig. 5 was of interest. The gun tube curvature starts to influence the projectile motion as the bore-rider reaches the area. Thus, another point located $80 \mathrm{~mm}$ from the tip of the projectile nose in the tungsten penetrator was chosen. The center of gravity (c.g.) that is usually used to represent the motion of the system was selected as well. Finally, a point in the back of the tail section was included so that the relative motion between the nose and the tail can be assessed. Figure 6(a) and (b) show the computed vertical and lateral displacement responses, respectively, at the selected locations. It appears that the balloting motion at the point of the projectile nose was significant. The relative displacement between the nose and the tail could be as high as $0.2 \mathrm{~mm}$. The sway of the tail had a magnitude three times higher than the lateral displacement of the barrel. The c.g. and tungsten points fairly followed the gun tube deformation shape in both directions, which implies that the sole use of the c.g. responses for structural integrity analysis, especially for the components mounted at the nose and tail areas, is apparently inappropriate.

Furthermore, the vertical and lateral velocity responses at the selected locations were also obtained and shown in Fig. 7(a) and (b), respectively. It can be seen that the oscillation frequency at the nose was much higher than that in the other region. Overall, the responses at the nose were dominant, and larger barrel deformation contributed to higher transverse velocity. Figure 8(a) and (b) demonstrate the computed vertical and lateral acceleration responses, respectively. Note that the acceleration varies substantially from one point to another over the projectile. The average value from each cross section at the selected locations was thus used. A maximum acceleration around 10,000 g's (acceleration-to-gravity ratio) was obtained in the nose area. This additional inertia force could have significant impact on electronics installed in the area and should be cautiously evaluated.

\subsection{Stochastic modeling and analysis}

As prescribed, the centerline variations of a gun barrel may be attributed to a variety of factors. In order to gain better understanding of projectile balloting, a parametric model was created to simulate the gun barrel with which comprehensive gun tube flexures can be studied. In accordance with the profile of measured centerline variations from a large number of experimental gun barrels [9], four fundamental shape variables were adopted and their deformation magnitudes were determined. Briefly speaking, the gun barrel was equally divided into four areas, which yielded five cross sections named letters A (muzzle), B, C, D and E (breech) as illustrated in Fig. 9. The nodes of a section were uniformly displaced a single unit each time while the remaining sections stayed unchanged. A second order biasing factor was used for the morphing so that the continuity of the slope along the flexed gun tube retained. The deformation shown in Fig. 9 is magnified for visibility.

Typically, the barrels in sections A and B exhibited higher deviations; a total of five levels was assigned. Sections $\mathrm{C}$ and $\mathrm{D}$ usually showed smaller variations and therefore, only three levels were used. All the nodes in section $\mathrm{E}$ were completely restrained since they were connected to the breech area. The values of the absolute lateral displacements at the selected sections are given in Table 2. The numbers in parentheses represent the ratio to the gun length. To investigate the overall effects of the barrel curvature on the projectile responses, a design-of-experiments (DOE) technique was adopted. In this study, a full factorial design was employed to generate an array of barrel shapes, i.e., 
(a)

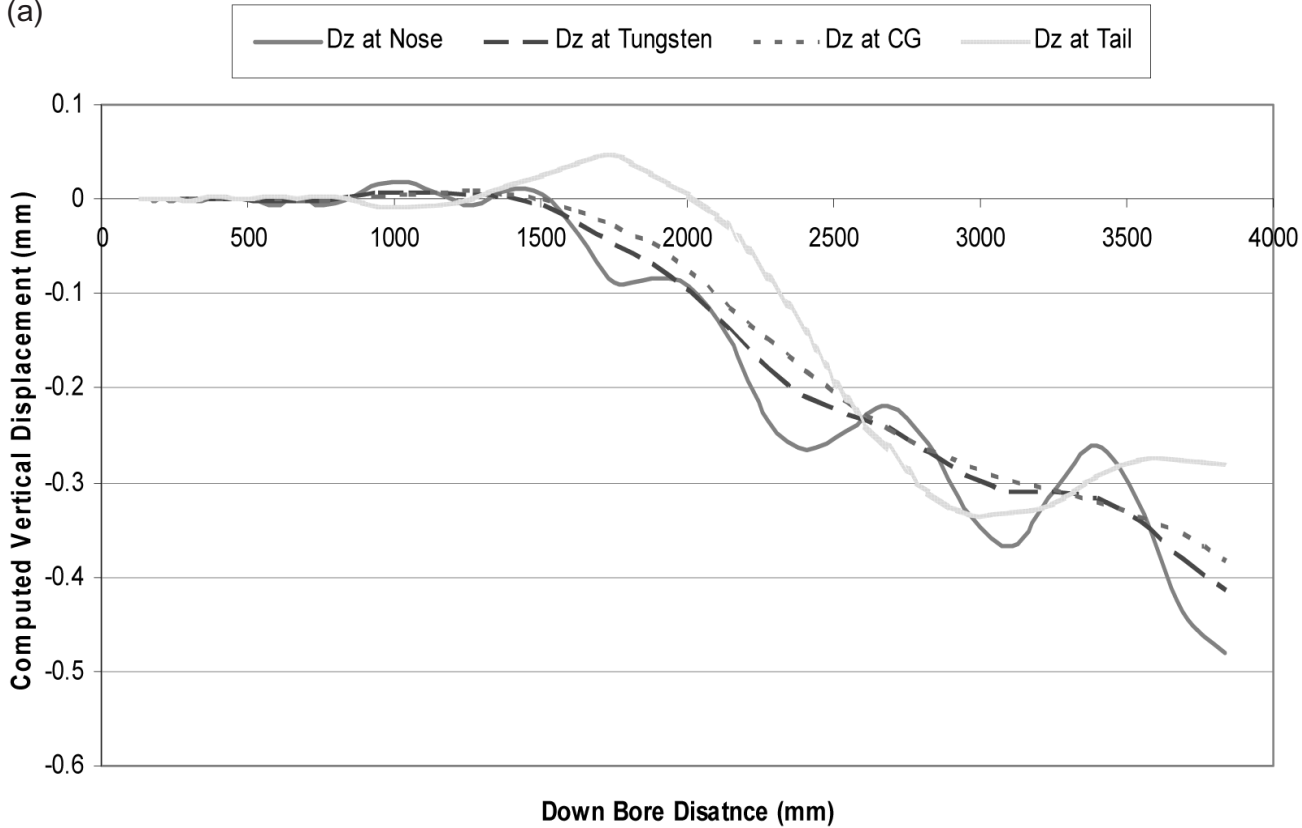

(b)

$$
\text { -Dy at Nose - - Dy at Tungsten - - - Dy at CG —Dy at Tail }
$$

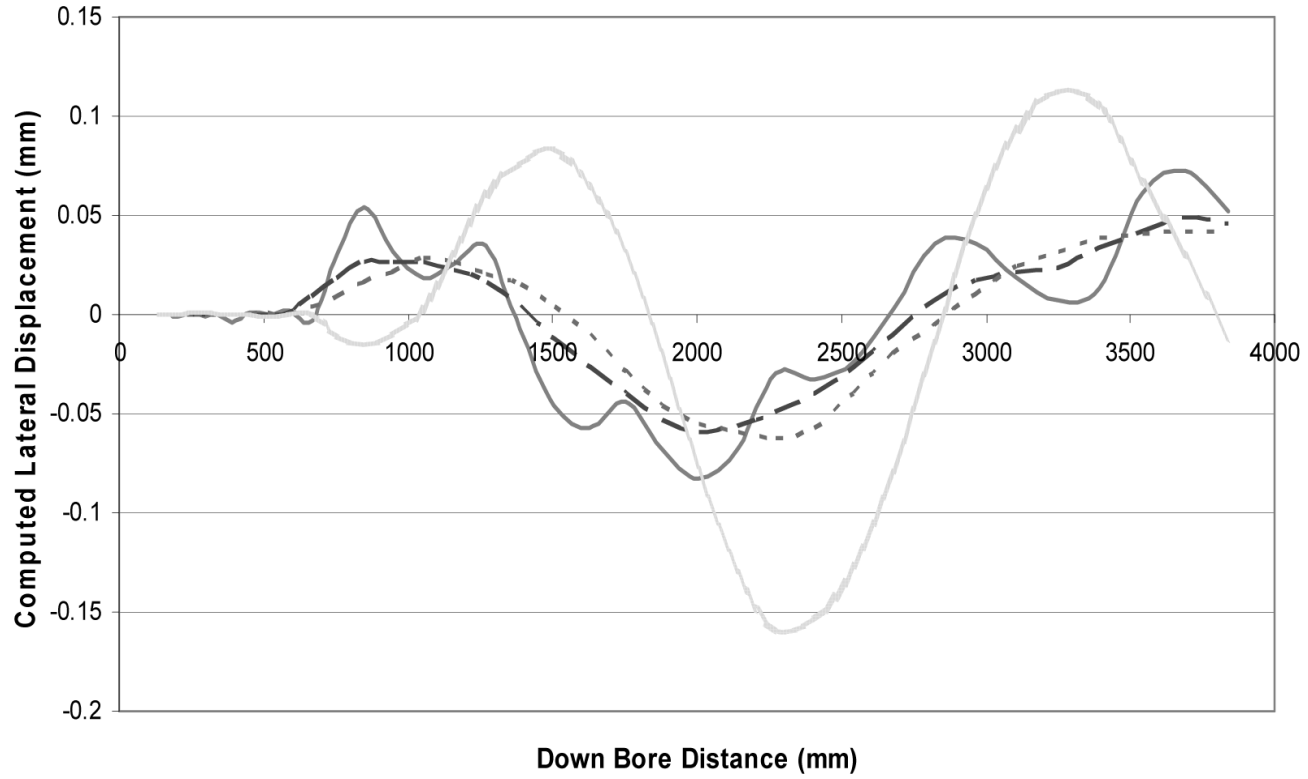

Fig. 6. Computed displacement responses at selected locations in (a) vertical and (b) lateral directions. 


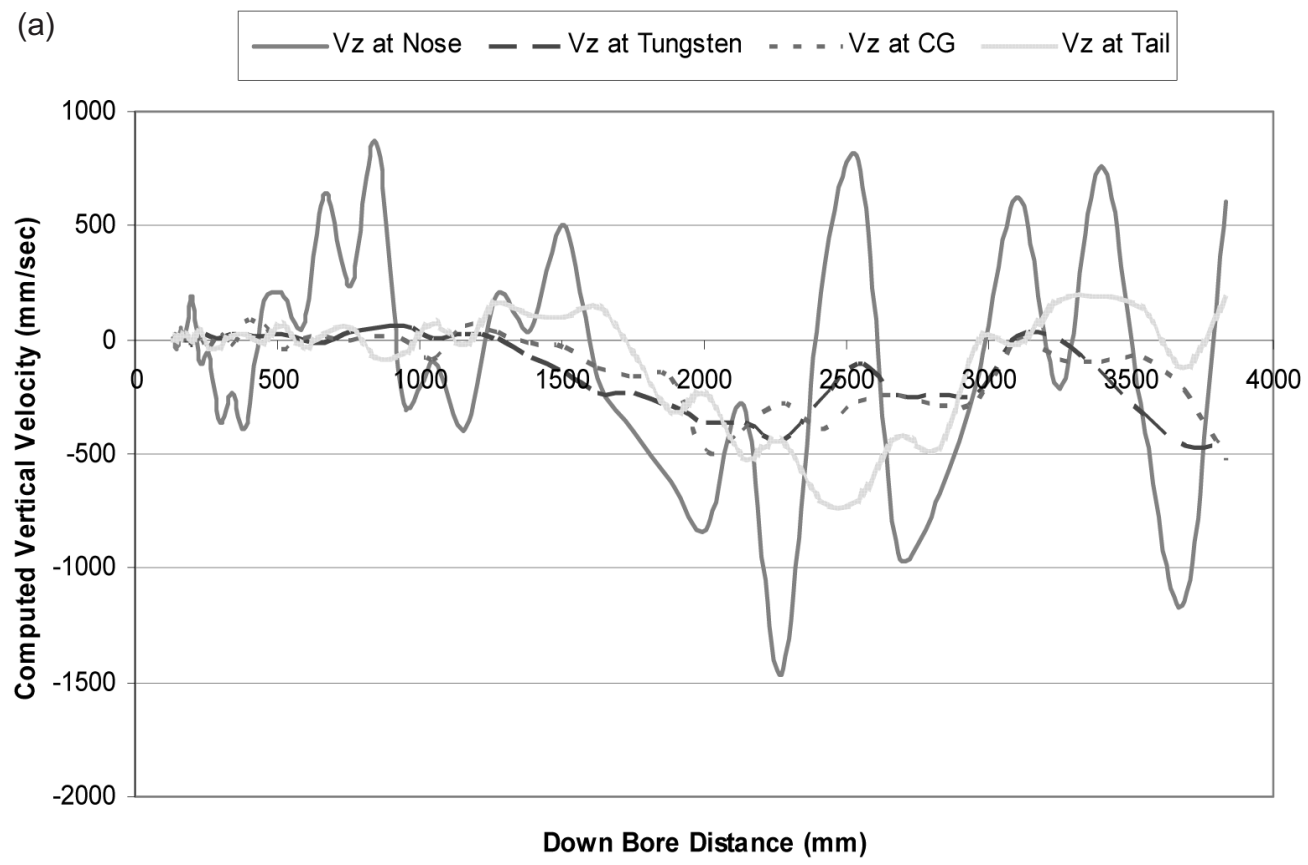

(b)
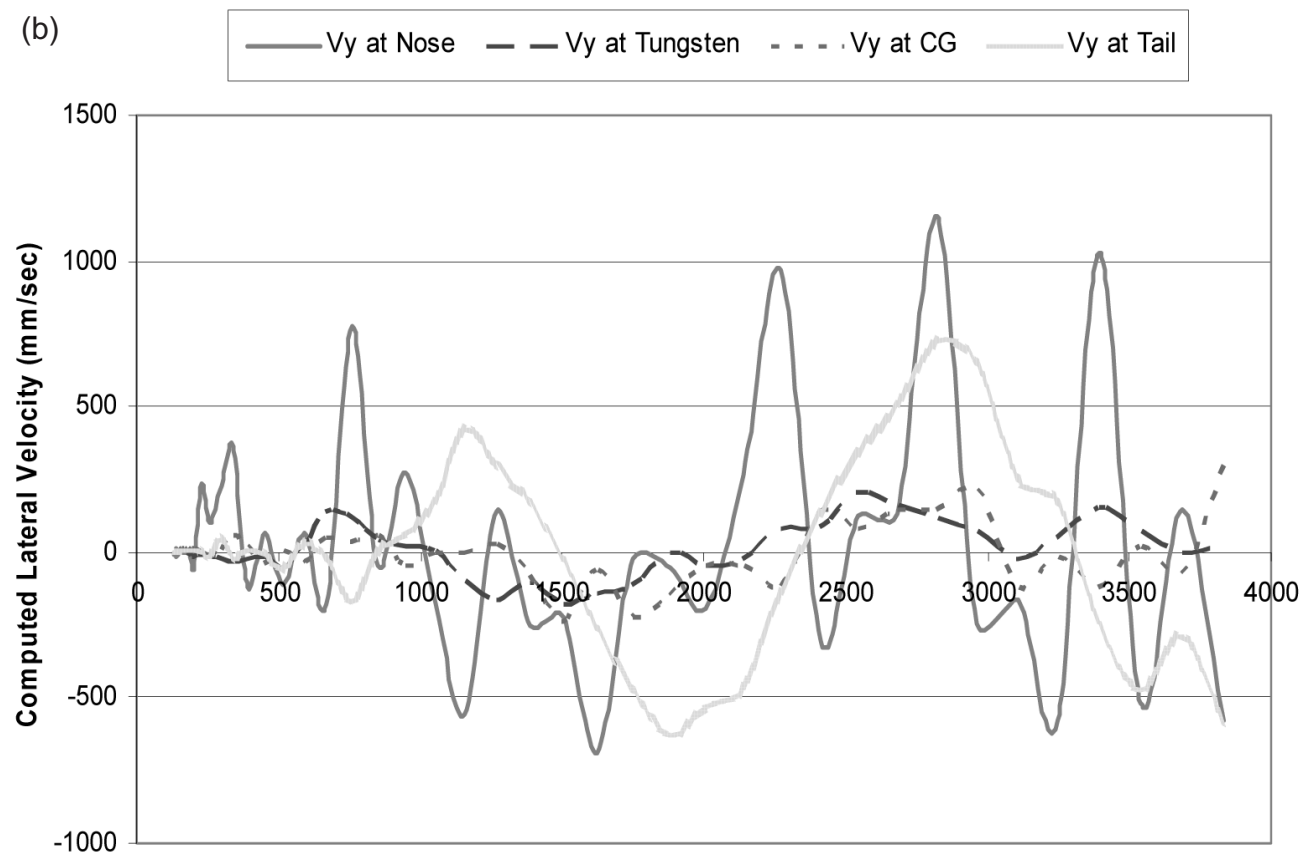

Down Bore Distance $(\mathrm{mm})$

Fig. 7. Computed velocity responses at selected locations in (a) vertical and (b) lateral directions. 


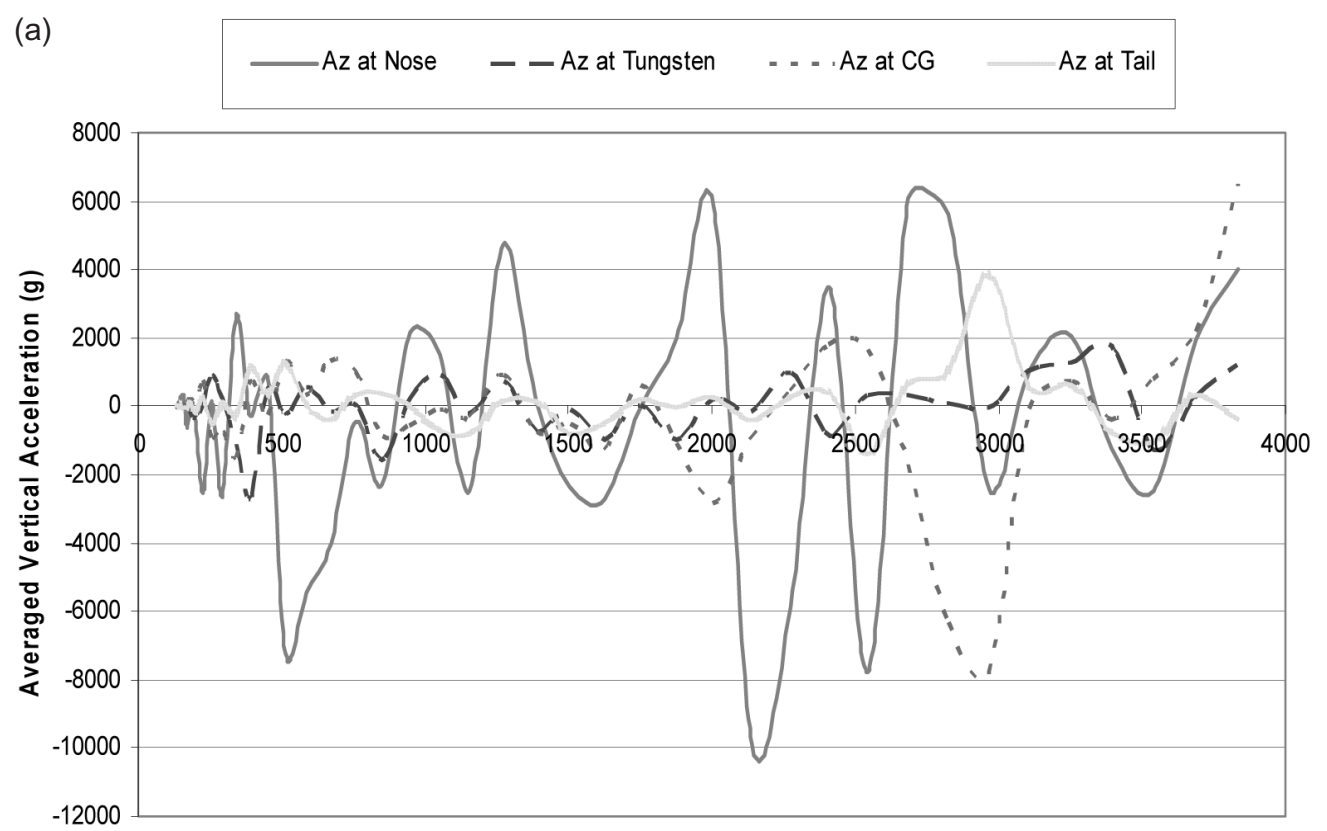

Down Bore Distance $(\mathrm{mm})$

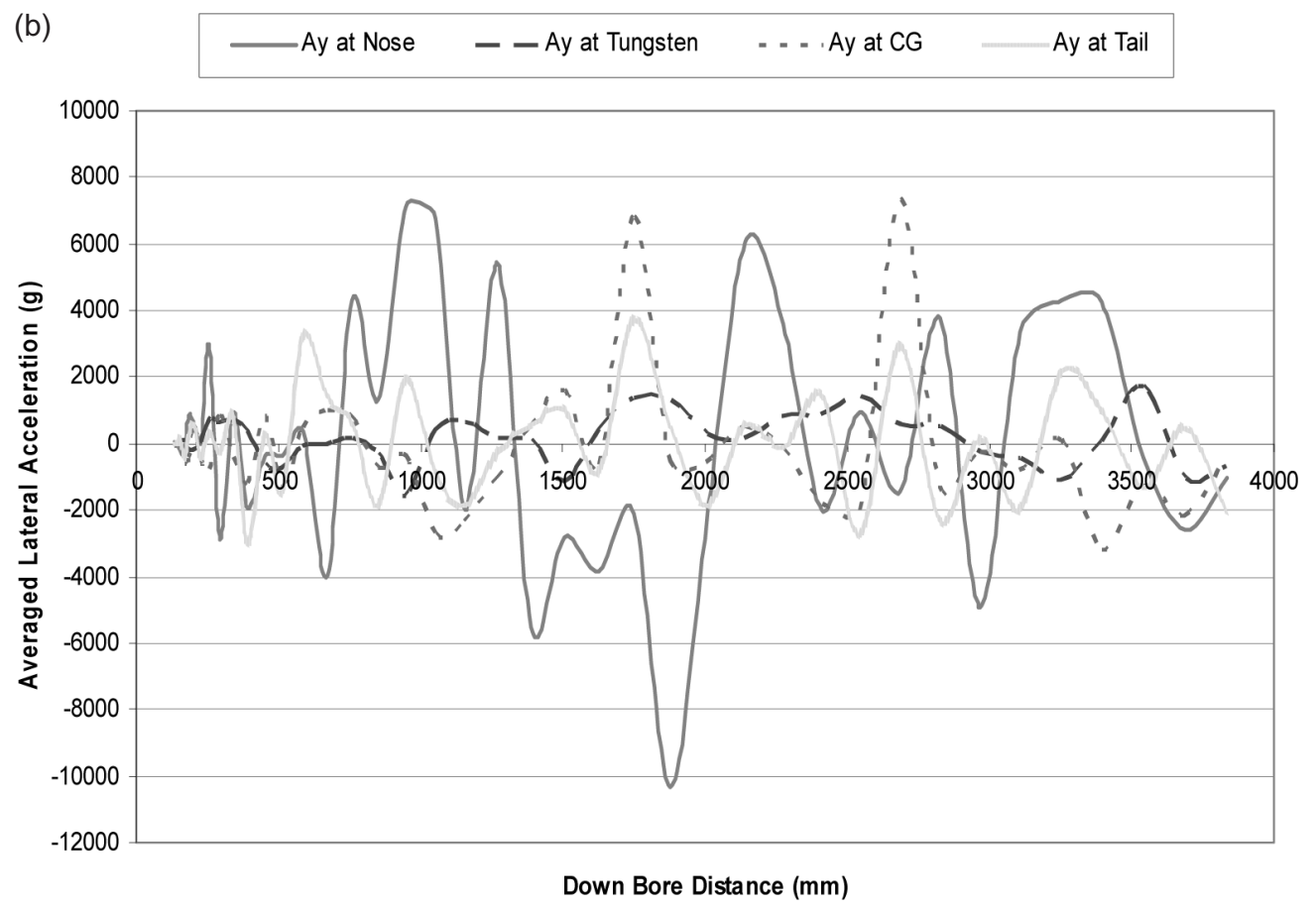

Fig. 8. Computed acceleration responses at selected locations in (a) vertical and (b) lateral directions. 
Table 2

Absolute lateral displacement ( $\mathrm{mm}$ ) of a gun barrel at five chosen sections

\begin{tabular}{lccccc}
\hline & Section E & Section D & Section C & Section B & Section A \\
\hline Level 1 & 0 & $0.03(0.0008 \%)$ & $0.05(0.0013 \%)$ & $0.21(0.0055 \%)$ & $0.25(0.0065 \%)$ \\
Level 2 & 0 & 0 & 0.105 & 0.125 \\
Level 3 & -0.03 & -0.05 & 0 & 0 \\
Level 4 & & & -0.105 & -0.125 \\
Level 5 & & & -0.21 & -0.25 \\
\hline
\end{tabular}

(a) Shape 1
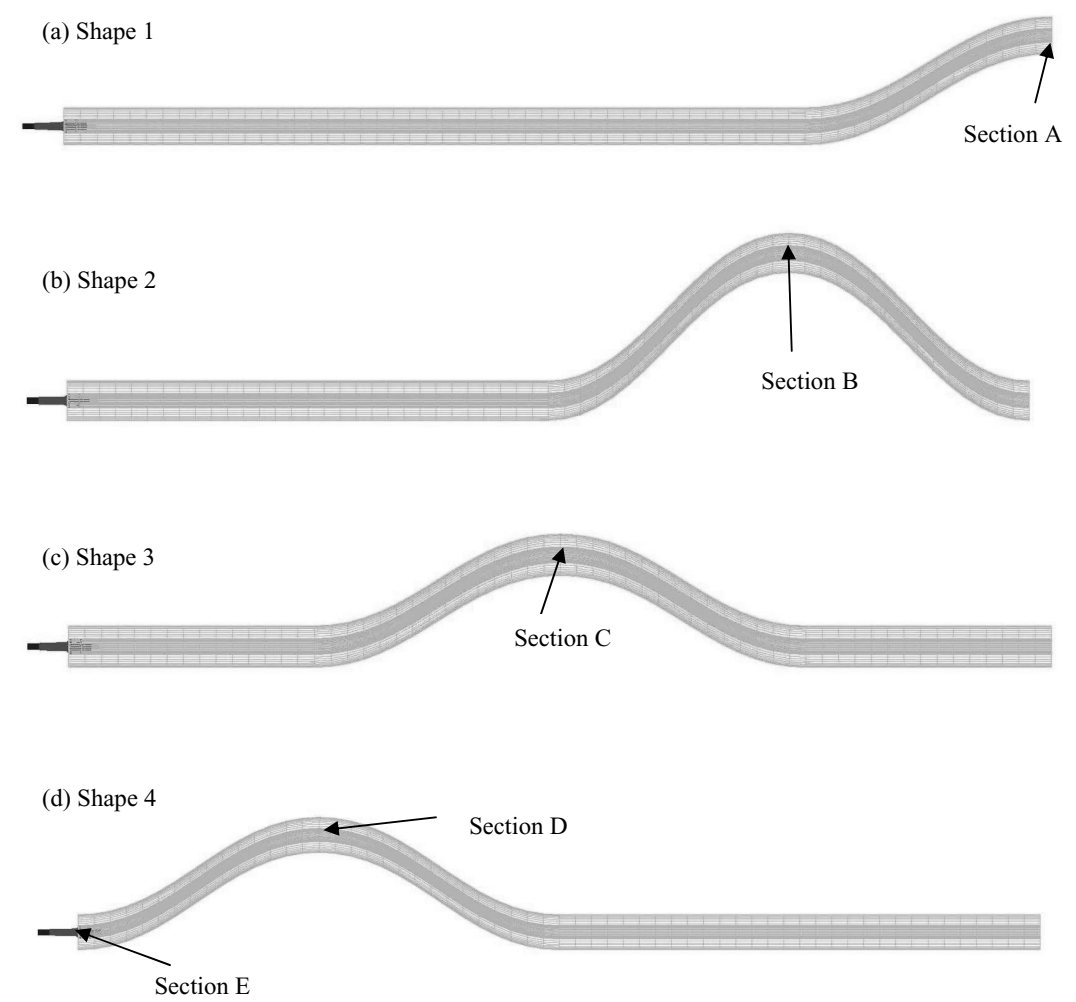

Fig. 9. Display of four fundamental deflection shapes of a gun barrel.

225 distinct deformed barrels because no prior knowledge in this aspect could warrant a fractional factor design. The combination of the experimental design is expected to well represent the spectrum of the gun tube curvature. An in-bore dynamic analysis was then performed on each of the 225 design cases and the time history of the lateral displacement response at the projectile's c.g. was obtained for each design case.

Note that the prescribed deterministic analysis required 48 central processing unit (CPU) hours of execution time. To be able to run through the 225 design cases, the geometry of the projectile was slightly simplified to gain computational efficiency. Specifically, the fins and the windscreen were removed and substituted with equivalent weight that was imposed onto the neighboring components do that the system's c.g. remained at the same location. In addition, the configuration of sabot was refined so that the total mass of the projectile system reduced to $1.02 \mathrm{~kg}$ from $1.26 \mathrm{~kg}$. The simplified model is shown in Fig. 10.

\section{Balloting in time domain}

The projectile balloting responses at c.g. were first investigated in time domain. The time history of the average lateral displacement based on the 225 simulated barrels is given in Fig. 11, i.e., the solid line in the middle. Because 


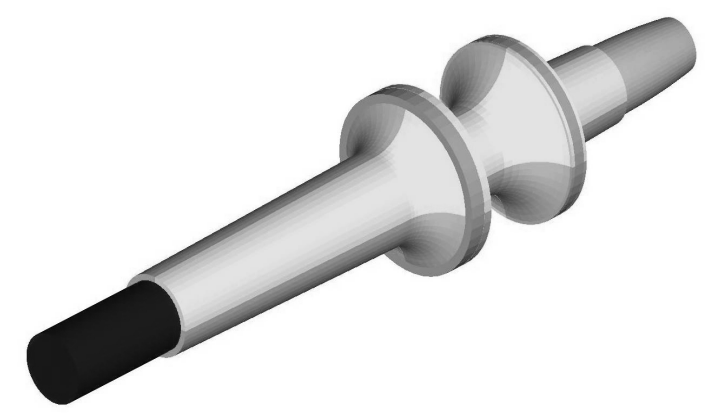

Fig. 10. Simplified model of the precision guided projectile.

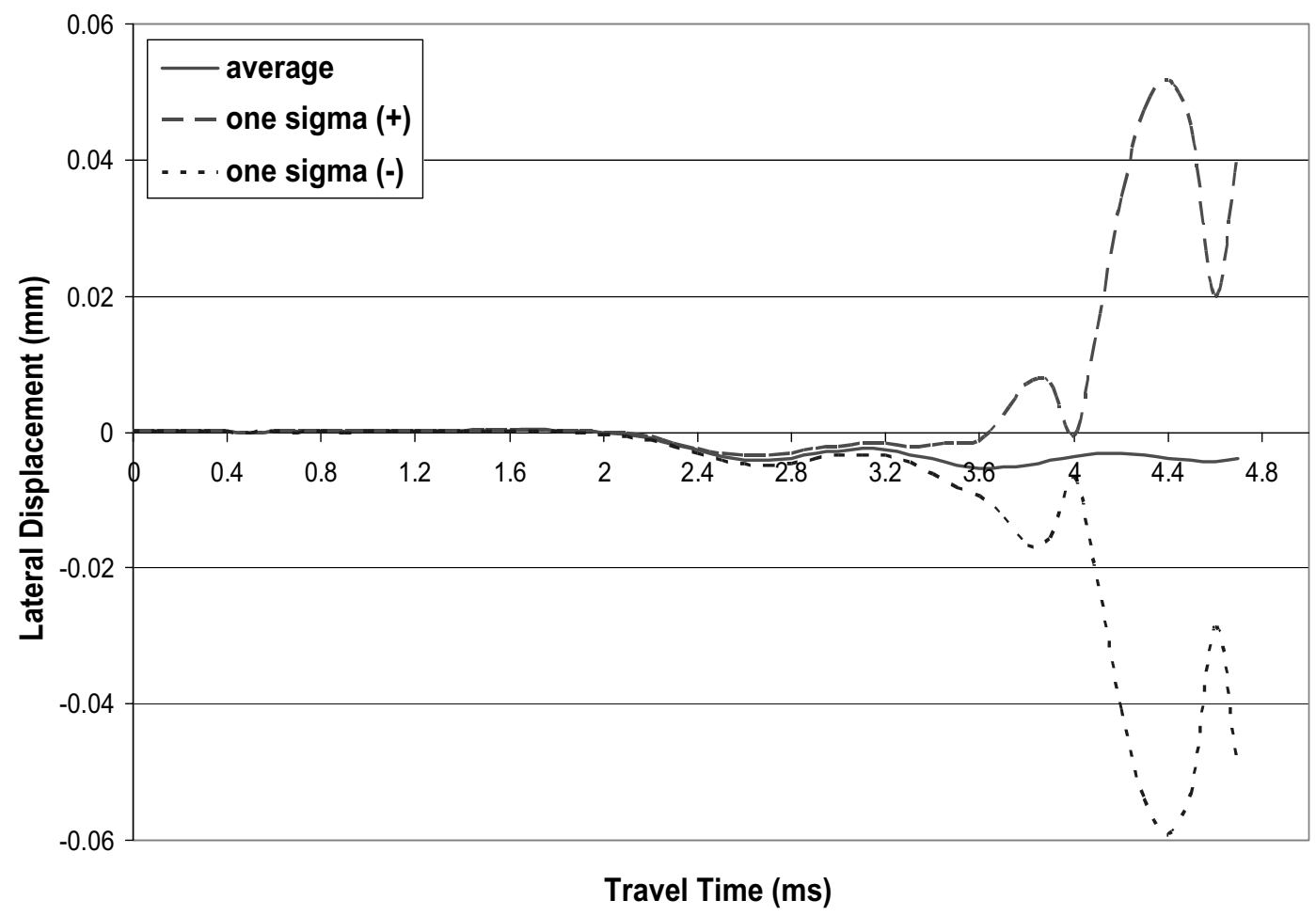

Fig. 11. Plot of the average c.g. lateral displacement $\pm 1 \sigma$ for 225 distinct barrels.

of the symmetry in the DOE design, the average values as expected were virtually zero. The dashed line above the mean curve represents the average value plus one standard deviation and the one below the average value minus one standard deviation. It can be seen that a maximum standard deviation of $0.05545 \mathrm{~mm}$ took place $4.4 \mathrm{~ms}$ from ignition. The projectile started to deviate from the center at $2.1 \mathrm{~ms}$ and the deviation greatly increased as the projectile moved closer to the muzzle. This implied that the barrel shape variables 1 and 2 played a vital role in determining the projectile movement. The barrel shapes that invoked the maximum absolute lateral displacement of the projectile are given in Table 3. The c.g. of the projectile displaced $0.1071 \mathrm{~mm}$ on one side (positive direction) and $0.1145 \mathrm{~mm}$ on the other side. Understandably, the shapes that had the highest variation levels with staggered sign yielded the critical results.

To be able to compare the projectile movement explicitly among the barrel designs, seven representative cases were chosen. The details of the selected barrel shapes are given in Table 4. Cases 1 through 4 portray the highest deformation level at each section alone. Each stands for one single curvature along the gun tube. Case 5 depicts a gun barrel with perfect straightness, i.e., all values of the shape variable at zeroes. Case 6 represents the largest 
Table 3

Design cases that have the critical absolute lateral displacements

\begin{tabular}{lrrrrc}
\hline Case & Shape 1 & \multicolumn{1}{c}{ Shape 2 } & Shape 3 & Shape 4 & Displacement Value \\
\hline Maximum positive displacement & 0.25 & -0.21 & 0.05 & -0.03 & $0.1071 \mathrm{~mm}$ \\
Maximum negative displacement & -0.25 & 0.21 & -0.05 & 0.03 & $-0.1145 \mathrm{~mm}$ \\
\hline
\end{tabular}

Table 4

Barrel shape values (mm) of seven representative cases

\begin{tabular}{ccccc}
\hline Case & Shape 1 & Shape 2 & Shape 3 & Shape 4 \\
\hline 1 & -0.25 & 0 & 0 & 0 \\
2 & 0 & -0.21 & 0 & 0 \\
3 & 0 & 0 & -0.05 & 0 \\
4 & 0 & 0 & 0 & -0.03 \\
5 & 0 & 0 & 0 & 0 \\
6 & -0.25 & 0.21 & -0.05 & 0.03 \\
7 & 0.25 & -0.105 & 0.05 & -0.03 \\
\hline
\end{tabular}

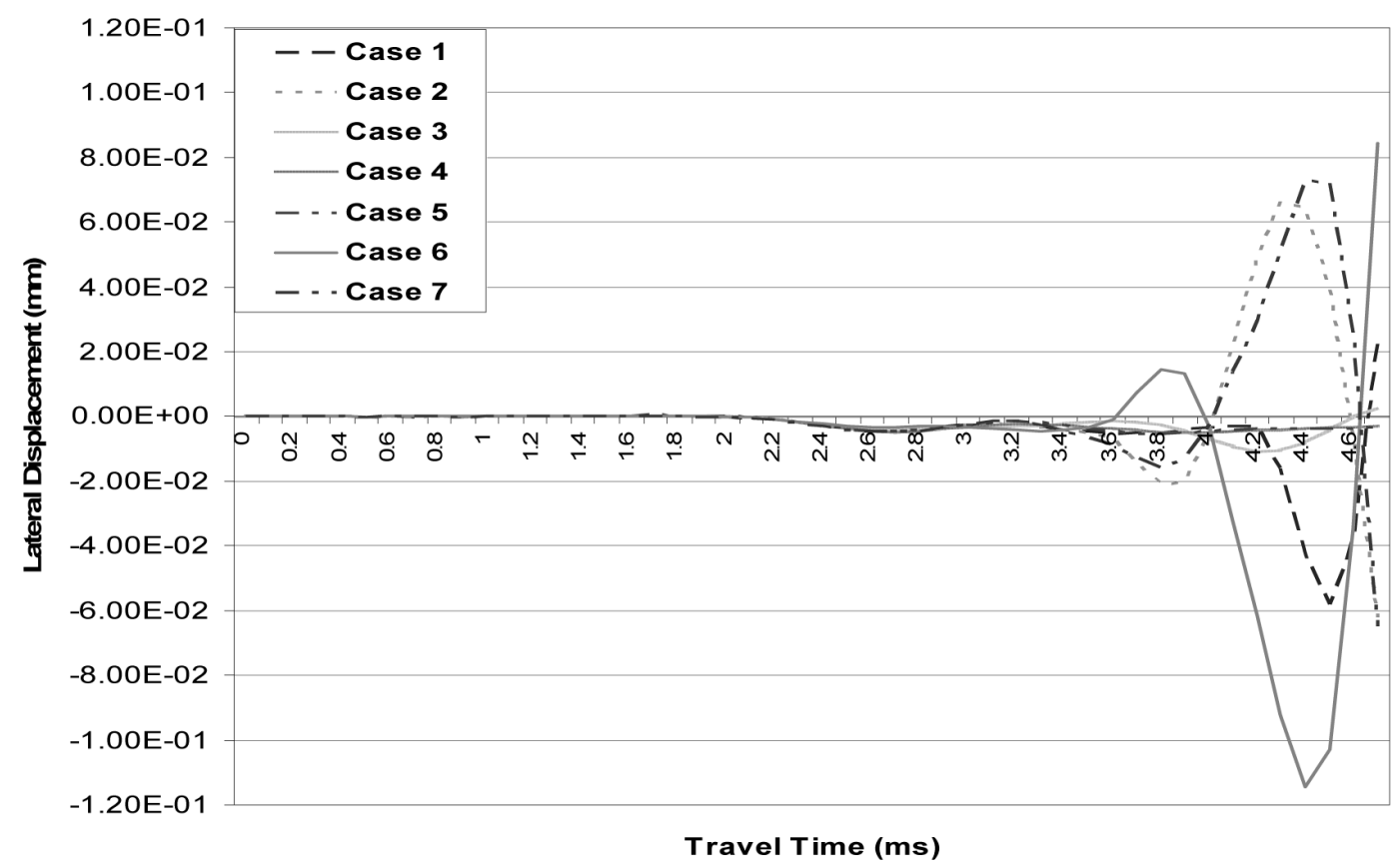

Fig. 12. Time history of lateral displacements for seven representative barrel shapes.

possible curvature of study as previously discovered. Finally, Case 7 describes a smaller bending level for the shape variable 2 as well as sign shift in comparison with those in Case 6 . The goal was to evaluate how the changes would affect the projectile movement. The time history of the absolute lateral displacements for the selected seven cases is shown in Fig. 12. Not surprisingly, the projectile movement in Case 6 exhibited the highest value. The displacement of Case 1, i.e., $-0.058 \mathrm{~mm}$, was slightly lower than that of case 2, i.e., $0.064 \mathrm{~mm}$. One potential reason may be because the projectile did not reach the far end of the muzzle at the time instant of $4.7 \mathrm{~ms}$ so that the shape 1 curvature was not fully taken into effect. The discrepancy between Case 6 and Case 7 was significant. In particular, the sign of the curvature determined the direction of the projectile movement. Again, because of symmetric design on barrel shapes, the displacement response from Case 5, namely, when the barrel that had perfect straightness agreed well with the average response of the entire design set, i.e., the mean curve of Fig. 11. 


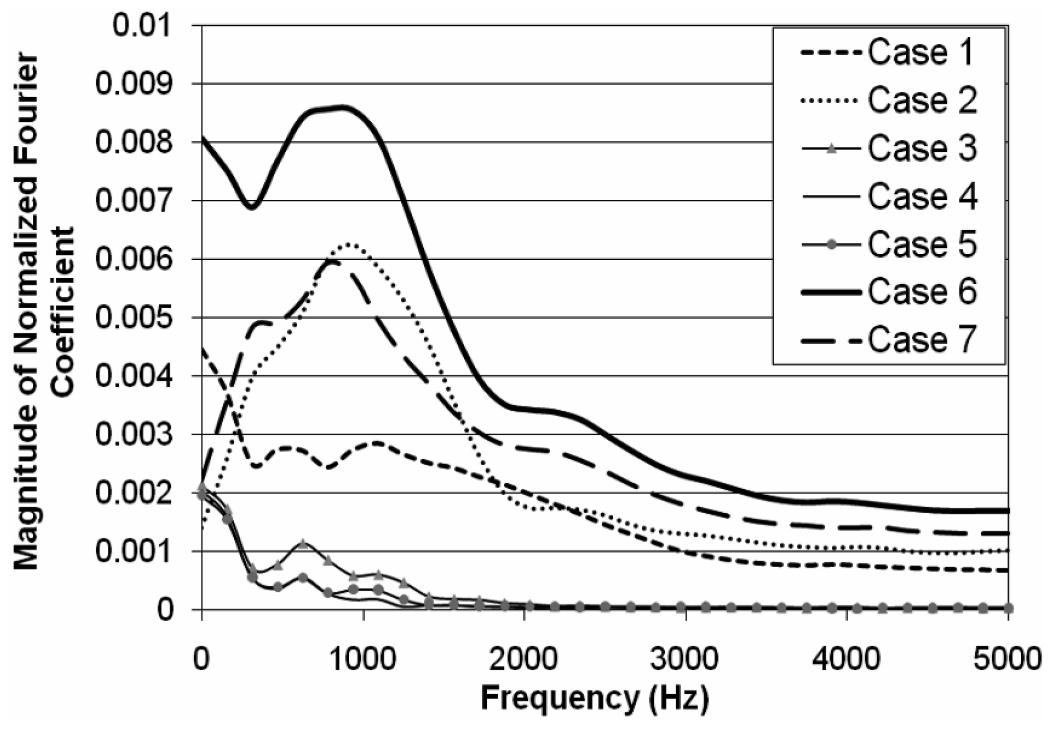

Fig. 13. Frequency spectrum of normalized Fourier coefficient for seven representative barrel shapes.

\section{Balloting in frequency domain}

The previously derived time series data of the projectile balloting may be converted to frequency domain through discrete Fourier transform so that periodic oscillations can be identified. Given a physical process represented by a function of time $f(t)$, i.e., balloting history, the function is sampled at $N$ times, $t_{k}=k \Delta t$ where $k=$ $0,1,2, \ldots, N-1$. From these $N$ measurements, $f_{k}, N$ complex amplitude, $F_{n}$, are determined which satisfy the $N$ equations

$$
F_{n}=\sum_{k=0}^{N-1} f_{k} e^{i k \frac{2 \pi n}{N}}
$$

The discrete Fourier expansion of the sampled function can then be expressed as

$$
f_{k}=\frac{1}{N} \sum_{n=0}^{N-1} F_{n} e^{-i n \frac{2 \pi k}{N}}
$$

Given the substitution $2 \pi k / N=\omega_{0} k \Delta t=\omega_{0} t_{k}$, Eq. (3) can be rewritten to

$$
f_{k}=\frac{1}{N} \sum_{n=0}^{N-1} F_{n} e^{-i n \omega_{0} t_{k}}
$$

The complex coefficients $F_{n}$ can be calculated from the time series data $f_{k}$. To expedite the transformation, a number of zeros were added to the time series so that the total number of samples becomes a power of 2, i.e., $N=2^{m}$.

Figure 13 shows the frequency spectrum of the magnitude of normalized Fourier coefficient for the previous seven cases. The spectrum is similar to the one transformed from a damped sine wave in time domain. It can be seen that most cases had the largest magnitude of Fourier coefficient in the frequency range between 700 and $900 \mathrm{~Hz}$. The magnitude decayed substantially beyond $1500 \mathrm{~Hz}$. Case 1 exhibited the strongest Fourier power, followed by Cases 2 and 7, which agrees with the analysis in time domain. To validate the spectrum pattern, three additional cases that showed unique barrel shapes were chosen and the details are given in Table 5. The frequency spectrum for the validation cases is depicted in Fig. 14. As shown, the magnitude of Fourier coefficient is highly sensitive to specific barrel curvature. However, it also demonstrates that the dominant frequency range still holds. Figure 15 displays the first two non-rigid-body vibration modes. The natural frequencies of approximately $1800 \mathrm{~Hz}$ and $4100 \mathrm{~Hz}$ were verified to deviate from the range. 
Table 5

Design cases for validation

\begin{tabular}{ccccc}
\hline Case & Shape 1 & Shape 2 & Shape 3 & Shape 4 \\
\hline 8 & -0.25 & 0 & 0.05 & 0 \\
9 & 0 & -0.21 & 0 & 0.03 \\
10 & 0.25 & 0 & -0.05 & 0.03 \\
\hline
\end{tabular}

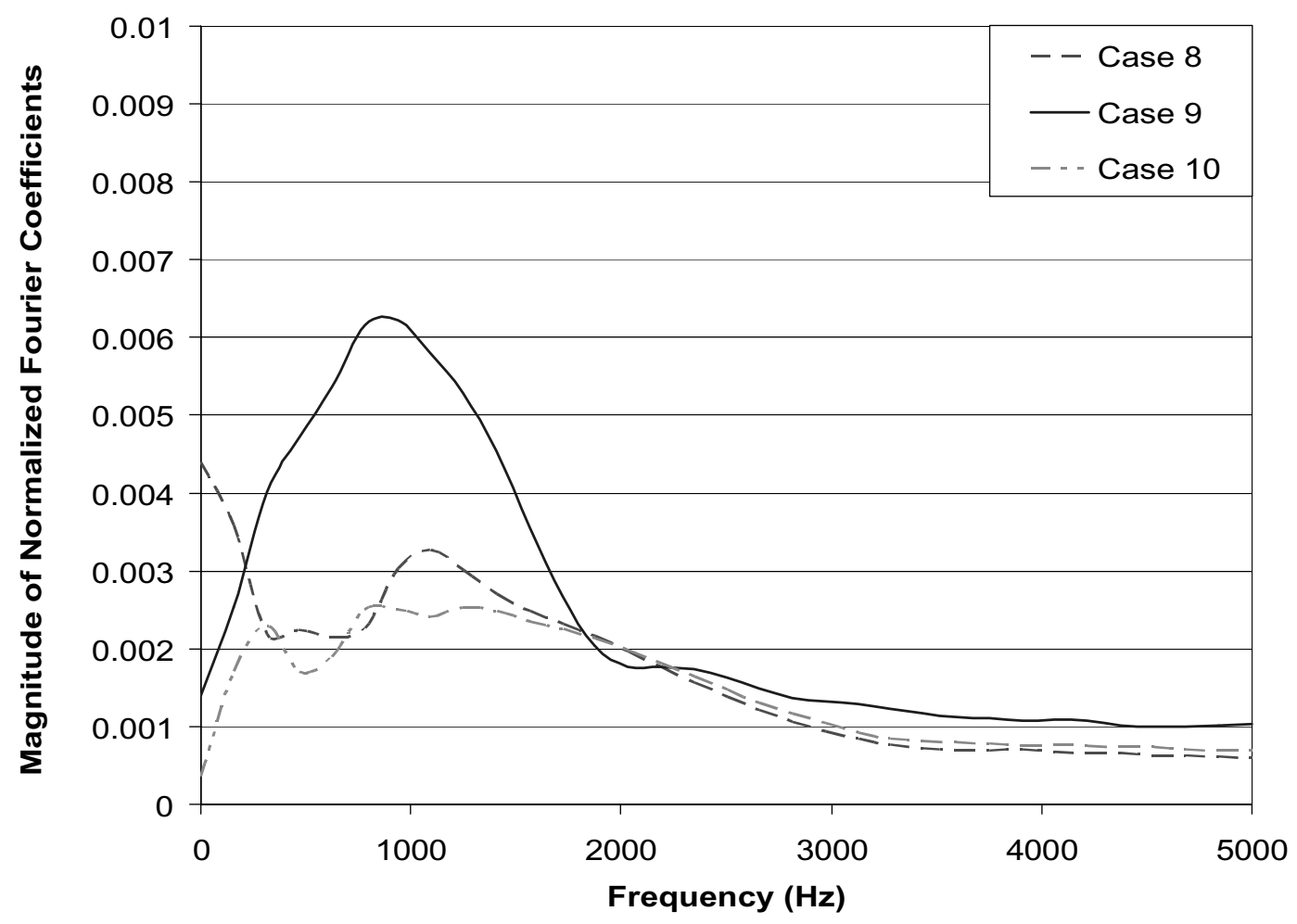

Fig. 14. Frequency spectrum of normalized Fourier coefficient for three validation cases.

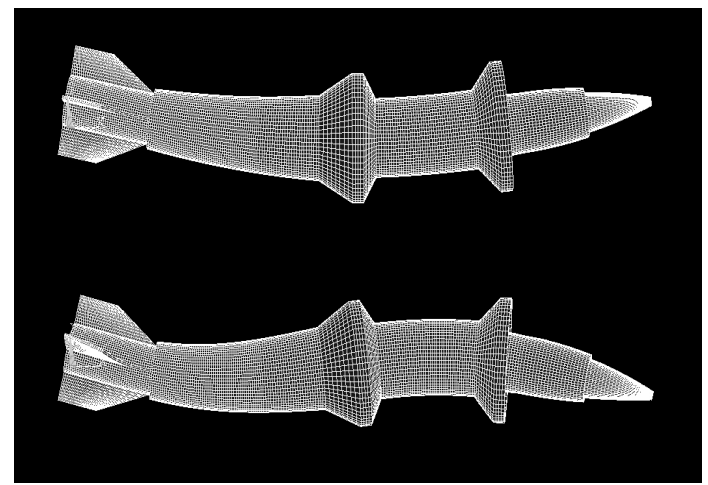

Fig. 15. Display of the first two non-rigid-body vibration modes.

\section{Summary}

Transverse motion of a traveling projectile through a deformed smooth gun barrel was investigated. The balloting phenomenon is fairly common because of the flexibility of sabot and projectile. The magnitude of balloting is 
expected to be magnified because of imperfect straightness of gun tube. An in-bore dynamic analysis of a finstabilized projectile and a deterministic gun barrel was conducted; centerline variations were modeled in both vertical and lateral directions based on measurement data. The displacement, velocity, and acceleration responses of the projectile were retrieved at four selected critical locations, i.e., nose, bore-rider, bulkhead, and tail. Relative displacement between the projectile nose and tail appeared to be significant. A balloting-induced lateral acceleration was found to be as high as $10,000 \mathrm{~g}$ at the nose area, which could be detrimental to mounted electronic devices.

Following the deterministic analysis, a novel approach to simulating an array of barrel shapes with the use of design of experiments methodology was proposed to examine in-bore projectile motion. This statistical study included a total of 225 distinct barrel shape simulations that were determined on the basis of a published gun barrel profile and generated with a parametric finite element model. The projectile movement at the c.g. was obtained and analyzed in time and frequency domains. The time history of the mean displacement along with one standard deviation range was derived. It was found that the gun tube curvature near muzzle area greatly contributed to the projectile lateral displacement. Seven representative barrel curvatures were chosen to reveal the significance. With the aide of fast Fourier transform, the time-dependent displacement responses were then evaluated in frequency domain. The computed magnitude of Fourier coefficient further demonstrates the substantial impact of specific barrel shapes. A frequency range between 700 and $900 \mathrm{~Hz}$ appeared to have the highest Fourier power across the simulation set, which suggests undesired natural frequency in the design of the projectile system.

\section{Acknowledgments}

The measured centerline variation data provided by Dr. Mark Bundy, my colleague at the US Army Research Laboratory, are greatly appreciated. This work was supported in part by a grant of high-performance computing time from the US Department of Defense High Performance Computing Modernization program at the ARL Major Shared Resource Center, Aberdeen Proving Ground, MD.

\section{References}

[1] E.H. Walker, Yawing and Balloting Motion of a Projectile in the Bore of a Gun with Application to Gun Tube Damage, Ballistic Research Laboratory Rept. MR-2411, 1974.

[2] K. Fansler, On Balloting of Projectile, Ballistic Research Laboratory Rept. MR-02831, 1978.

[3] P. Plostins, I. Celmins, J. Bornstein and J. Diebler, The Effect of Sabot Front Borerider Stiffness on the Launch Dynamics of Fin-Stabilized Kinetic Energy Ammunition, Ballistic Research Laboratory Rept. TR-3047, 1989.

[4] D. Lyon and K. Soencksen, Radial Stiffness and In-Bore Balloting Analysis for the M900 Projectile, US Army Research Laboratory Rept. TR-593, 1994

[5] T. Erline, Simulations Varying Projectile Sabot Front-Bell Stiffness and Its Effect on Dispersion, US Army Research Laboratory Rept. MR506,2001

[6] J. Newill, B. Burns and S. Wilkerson, Overview of Gun Dynamics Numerical Simulations, US Army Research Laboratory Rept. TR-1760, 1998.

[7] S. Chu, Balloting Motion of SLEKE Launch Packages in EM Railguns, IEEE Transactions on Magnetics 29(1) (1993), 769-774.

[8] D.W. Lodge, Use of the SIMBAD Gun Dynamics Code for modeling the In-Bore Dynamics of EM Launchers, Unite Kingdom Defense Evaluation and Research Agency Rept. ADP012473, 2001.

[9] M. Bundy, J. Newill, V. Marcopoli, M. Ng and C. Wells, A the In-Bore Dynamics of EM Launchers, Unite Kingdom Defense Evaluation and methodology for Characterizing Gun Barrel Flexure Due to Vehicle Motion, Shock and Vibration 8 (2001), $223-228$.

[10] J. Newill, J. Garner and M. Bundy, Methodology for Determining Optimal Tank Cannon Barrel Centerline Shape, US Army Research Laboratory Rept. TR-2813, 2002.

[11] J. Newill and M. Bundy, Gun Tube Selection Methodologies for Accuracy Testing, US Army Research Laboratory Rept. TR-3080, 2003. 

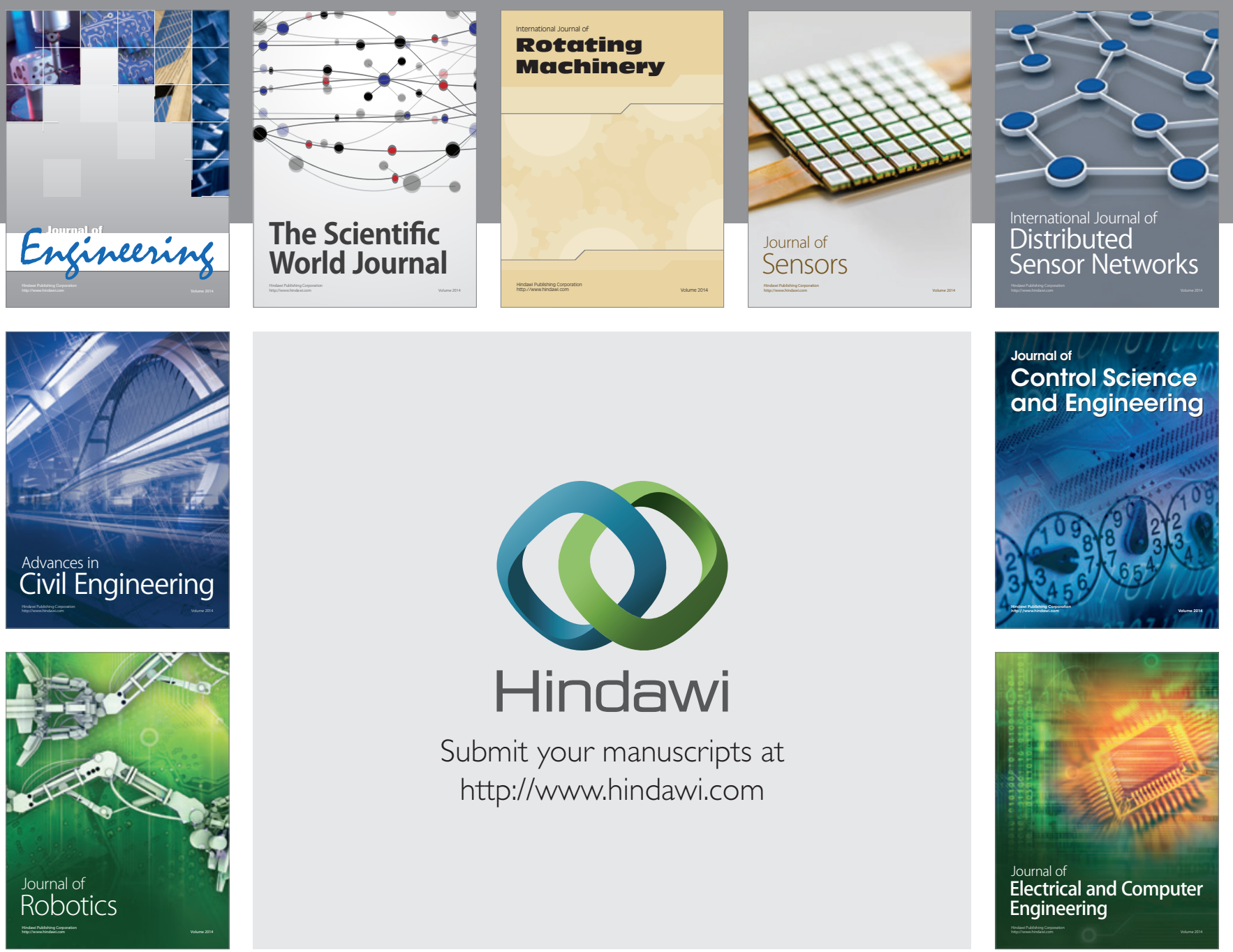

Submit your manuscripts at

http://www.hindawi.com
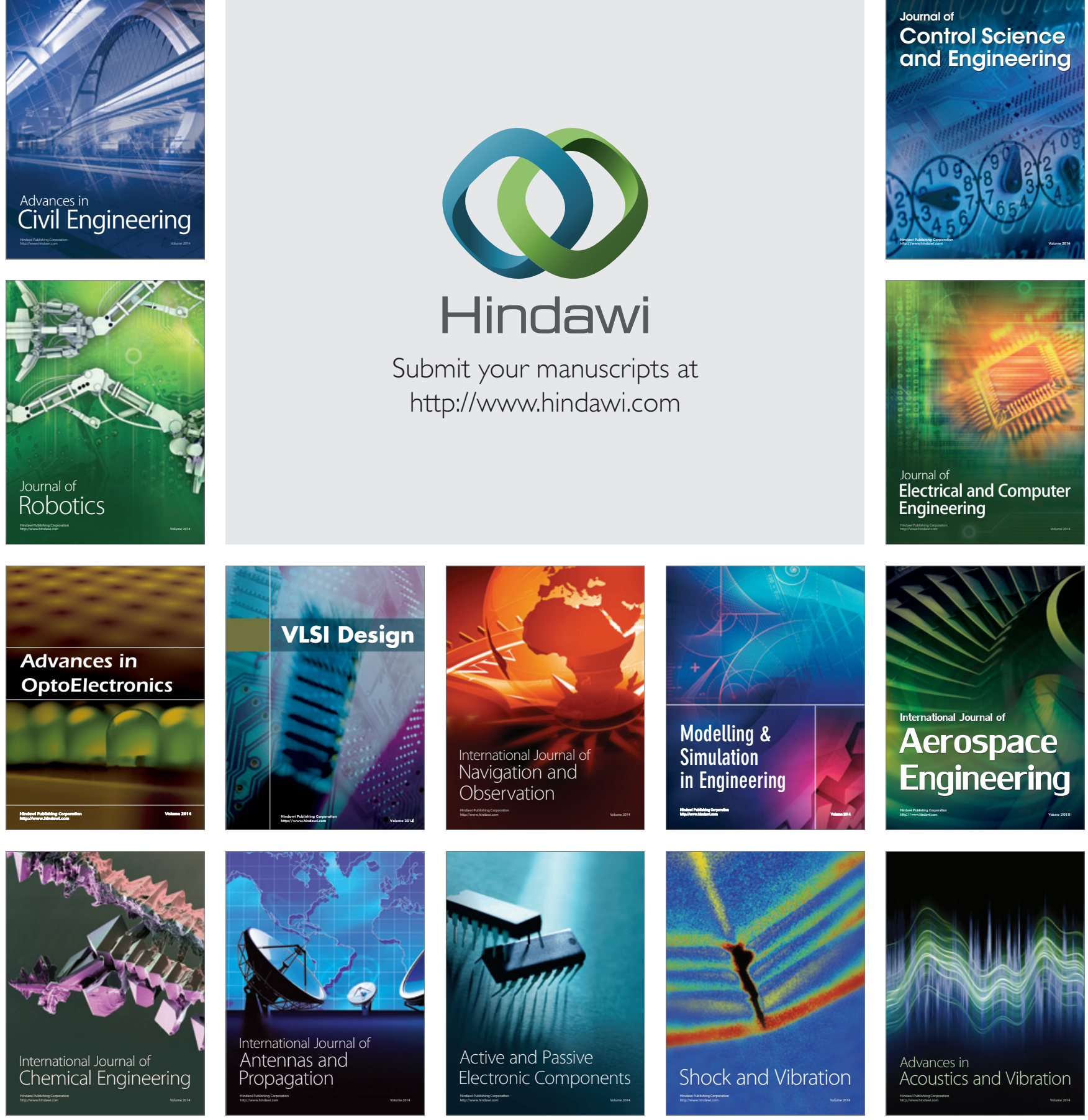